\title{
A contemporary facet on rohypnol: a date rape drug
}

\begin{abstract}
Rohypnol is the common name for a drug called Flunitrazepam, the slang term used is roofies. Rohypnol is believed to be most commonly used drug in commission of drug assisted Sexual assaults in the United States, the United Kingdom, and throughout Europe, Asia and South America and very popular in clubs and rave parties. This drug being colourless, odourless and flavourless is simply slipped in a drink, or mixed in any food supplement without being suspected and is used to robe, rape or harm people therefore infamously called as Date rape drugs. It is a strong hypnotic, a sedative ; an anticonvulsant; an anxiolytic ; an amnestic ; and skeletal muscle relaxant. Present paper concisely states about the effects of such drugs, scenarios, attempts to explore various analytical methods available \& challenges regarding its analysis posed before the toxicologist and law enforcing authorities. This communication has been sourced from scientific literature available in electronic databases and traditional literature available.
\end{abstract}

Keywords: rohypnol, hypnotic, sedative, central nervous system, toxicologist
Volume 4 Issue I - 2018

\author{
Priyanshu Jain, Navjot Kaur Kanwal \\ Department of Criminology and Forensic Science, Dr. H.S Gour \\ Central University, India
}

\author{
Correspondence: Navjot Kaur Kanwal, Department of \\ Criminology and Forensic Science Dr. H.S Gour Central \\ University, Sagar, India, Email kanwalnk@gmail.com
}

Received: December 04, 2017 | Published: January 08, 2018

\section{Introduction}

Date Rape drugs usually applies to the drugs that renders us incapable of saying no, it causes sedation, impaired motor skills, unconsciousness and memory loss. Since the mid-1990s the media and researchers have revealed the use of date rape drugs such as Rohypnol, GHB and ketamine. The assault facilitated through such drugs without the consent or through unacceptable consent of a person is known as drug facilitated sexual assault. Moreover these drugs are colourless, odourless and tasteless and can be easily slipped in a drink, without being suspected. ${ }^{1}$ Some of the other effects of these drugs are lost sense of time and identity, memory problems, numbness, loss of coordination, aggressive or violent behaviour, depression, high blood pressure, slurred speech, seizures, problems in breathing, loss of consciousness (black out) (Figure 1).

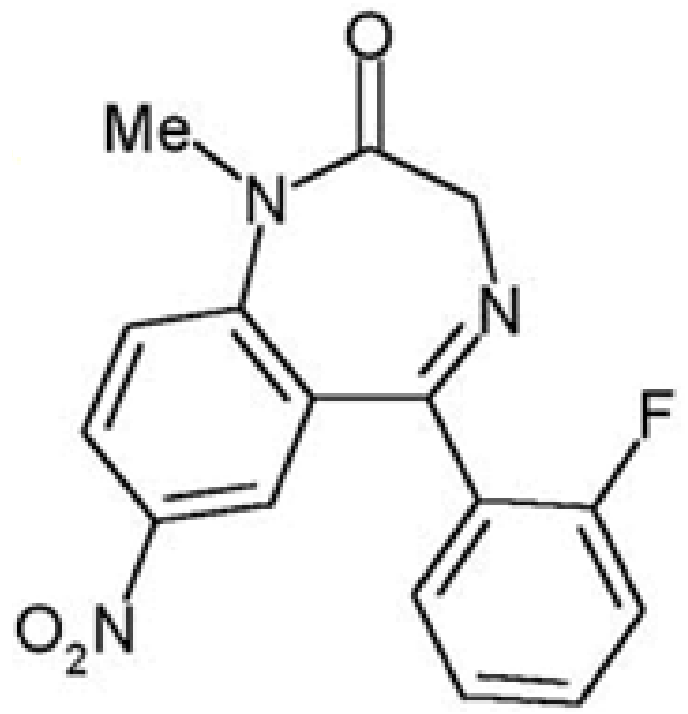

Figure I Rohypnol (5-(2-fluorophenyl)-I-methyl-7-nitro-IH-benzo[e][I,4] diazepin-2(3H)-one).
One of the infamous drug among Date rape drugs, a Benzodiazepine which is a central nervous system depressant. Roche (a healthcare and pharmaceutical company) started selling flunitrazepam (Rohypnol) in 1975. At first, hospitals used the drug when a patient needed a deep sleep. It was sold commercially in 1975 in Europe, and in the 1990s in the United States. The drug was given the brand name Rohypnol. It is similar to diazepam (such as Valium) but about 10 times more persuasive since it has much stronger affinity for the GABA receptor than diazepam. Flunitrazepam is readily $(80-90 \%)$ absorbed through the GI tract and metabolized almost completely by the liver. Its metabolism includes reduction to 7-aminoflunitrazepam and then to the $\mathrm{N}$-glucuronide, demethylation to the $\mathrm{N}$-demethyl metabolite, hydrolysis to the 3-OH metabolite and then to the O-glucuronide. Approximately $90 \%$ of its metabolites are excreted through the urine and $10 \%$ in the faeces. Deaths involving flunitrazepam have been reported when this drug is abused along with other CNS depressants, such as ethanol, but also due to overdose of flunitrazepam alone. It is easily accessible with some pet names like "roofies," "rope," and "roaches. ${ }^{2,3}$ It comes as a pill that dissolves in liquids; some of them are undersized, round, and white whereas newer pills are oval and green-gray in colour due to the presence of dye.

\section{Legal status of rohypnol}

Rohypnol is commonly prescribed as a sedative; there are over 50 countries around the globe which authorize its production, distribution and use. (Rohypnol Use in Different Cultures) The drug is most prominent in European countries, Columbia and Mexico. Other countries prescribe Rohypnol to aid sleep problems like insomnia and for general anesthesia. Rohypnol is also used to treat withdrawal symptoms of other drugs, such as crack or cocaine (Table 1).

\section{Various analytical procedures reported for the determination of Rohypnol in different matrixes}

Rohypnol will remain in the bloodstream for up to 60hours in the average person after ingestion. Some preferable samples for such drug is blood and urine but studies over the last few years have investigated 
the use of oral fluid as an alternative matrix to blood and urine, especially when non-intrusive and quick sampling procedures are important most recently hair are considered best sample for long term abuse of such drugs. The cups, bottles, drinking glasses and liquids left at scene of crime should also be collected and submitted for analysis. Some common methods for drug analysis include. Various studies have been reported which are claiming to produce a nail polish that will reveal the presence of "date rape drugs" such as Rohypnol and GHB by changing color in their presence. ${ }^{4-18}$ (Students Develop Nail Polish That Can Detect Date Rape Drugs) (Table 2).

Table I International legal scenario

\begin{tabular}{|c|c|}
\hline $\begin{array}{l}\text { United } \\
\text { States }\end{array}$ & $\begin{array}{l}\text { Not been approved by the Food and Drug Administration and is therefore illegal in the United States. The U.S. } \\
\text { government passed a law in } 1996 \text { known as the Drug Induced Rape Prevention and Punishment Act because of the high } \\
\text { number of sexual assault and rape cases related to Rohypnol use. }\end{array}$ \\
\hline Australia & Flunitrazepam is a Schedule 8 drug meaning that it is illegal to possess without a valid prescription or license. \\
\hline Canada & Added to Schedule I in 2012 \\
\hline Germany & $\begin{array}{l}\text { Flunitrazepam is available by prescription in Germany. Sold under the brand name "Rohypnol", produced by Roche, it } \\
\text { comes in } 10 \text { or } 20 \text { tablet packages at I mg per tablet }\end{array}$ \\
\hline Norway & It is a controlled substance and is a prescription-only drug \\
\hline Sweden & $\begin{array}{l}\text { Flunitrazepam is a Class } 2 \text { drug in Sweden, with most other benzodiazepines in Class } 4 \text {. Flunitrazepam is available as a } \\
\text { prescription drug under the brand names Flunitrazepam and Fluscand. Comes in } 20,50,100 \text {, and } 250 \text { tablet packages with } \\
\text { each tablet at } 0.5 \text { or } 1.0 \mathrm{mg} \text {. }\end{array}$ \\
\hline France & Since 2016 Flunitrazepam is not marketed \\
\hline $\begin{array}{l}\text { United } \\
\text { Kingdom }\end{array}$ & Flunitrazepam is not licensed for medical use and is a controlled drug under Schedule 3 and Class C \\
\hline Japan & $\begin{array}{l}\text { Marketed by Japanese pharmaceutical company Chugai and is used for the treatment of insomnia as well as used for } \\
\text { preanesthetic medication(Flunitrazepam) }\end{array}$ \\
\hline
\end{tabular}

Table 2 Various analytical procedures reported for the determination of rohypnol in different matrixes

\begin{tabular}{|c|c|c|c|}
\hline Analytical method & Matrix & Detection limit & Citation \\
\hline Screen Printed Graphene Electrodes (SPGrE) & Buffer, Beverage & $6 \mathrm{ng} / \mathrm{mL}$ & Enriqueta Garcia-Gutierrez ${ }^{5}$ \\
\hline SPGE & Buffer, Beverage & $0.47 \mu \mathrm{g} / \mathrm{mL}$ & Lledo-Fernandez et al." \\
\hline LCMS-MS & Human Serum & $0.2 \mathrm{ng} / \mathrm{mL}$ & Moore et al. ${ }^{12}$ \\
\hline Fluorescence spectroscopy & Beverage & Ing/mL & Leesakul et al. ${ }^{10}$ \\
\hline Desorption Electrospray & Beverages & $15 \mathrm{ng} / \mathrm{mL}$ & D'Aloise $^{3}$ \\
\hline GC-MS & Oral Saliva & $0.1 \mathrm{pg} / \mathrm{mL}$ & Samyn et al. ${ }^{14}$ \\
\hline
\end{tabular}

\section{Challenges}

Drug-facilitated sexual assault victims often do not report the incident in a timely manner because of amnesia and doubt about what may have happened and possibly other psychological reasons (including embarrassment, fear, rejection, denial, and mistrust in authorities). If reported does not lead to positive results due to length of time elapsed in collection of urine and blood samples.

\section{Conclusion}

Rohypnol is the most popular drug used for perpetrating sexual offences due to their favourable physical properties like colourless, odourless and tasteless. This drug is usually taken in addition to alcohol and marijuana, are the most common in cases of substancerelated sexual assaults today. This drug is legal when lawfully used under medical prescription. But that doesn't mean they are safe as these drugs can lead to dependency and can impair if abused, therefore should only be used under a doctor's care and order. It has been observed that in most of crimes facilitated by this drug is being lanced by persons of acquaintance and even men fall prey to date rape drug gangs. Police or investigators should pay importance in collecting samples immediately after reporting of incident (i.e. Blood and Urine). 


\section{Acknowledgements}

None.

\section{Conflict of interest}

The author declares no conflict of interest.

\section{References}

1. Banerjee PK. Presynaptic gamma-hydroxybutyric acid (GHB) and gamma-aminobutyric acidB (GABAB) receptor-mediated release of GABA and glutamate (GLU) in rat thalamic ventrobasal nucleus (VB): a possible mechanism for the generation of absence-like seizures induced by GHB. J Pharmacol Exp Ther. 1995;273(3):1534-1543.

2. Burgess AW, Hazelwood RR. Practical aspects of rape investigation: a multidisciplinary approach. 5th ed. USA: CRC Press; 2009. p. 1-462.

3. D'Aloise P, Chen H. Rapid determination of flunitrazepam in alcoholic beverages by desorption electrospray ionization-mass spectrometry. Sci Justice. 2012;52(1):2-8.

4. Dimitrijevic N, Dzitoyeva S, Satta R, et al. Drosophila GABA(B) receptors are involved in behavioral effects of gamma-hydroxybutyric acid (GHB). Eur J Pharmacol. 2005;519(3):246-252.

5. Enriqueta Garcia-Gutierrez, Fernandez CL. Electroanalytical Sensing of Flunitrazepam Based on Screen Printed Graphene Electrodes. Chemosensors. 2013;1:68-77.

6. Erowid. Flunitrazepam (Rohypnol) Legal Status. USA: The Vaults of Erowid; 2017.

7. https://en.wikipedia.org/wiki/Flunitrazepam
8. Gahlinger PM. Illegal Drugs: A Complete Guide to Their History, Chemistry, Use and Abuse. Medical Journal Gahlinger. 2000:558-561.

9. Garcia-Gutierrez E, Lledo-Fernandez C. The electro analytical sensing of flunitrazepam (rohypnol) and 7-amino flunitrazepam in oral fluid, urine and alcoholic beverages. Univers J Chem. 2013;1:121-127.

10. Leesakul N, Pongampai S, Kanatharana P, et al. A new screening method for flunitrazepam in vodka and tequila by fluorescence spectroscopy. Luminescence. 2013;28(1):76-83.

11. Lledo Fernandez, E GG. Electro analytical Sensing of Flunitrazepam Based on Screen Printed Graphene Electrodes. Chemosensors. 2013;1:68-77.

12. Moore C, Coulter C, Crompton K, et al. Determination of benzodiazepines in oral fluid using LC-MS-MS. J Anal Toxicol. 2007;31(9):596-600.

13. Rohypnol Use in Different Cultures. 2017.

14. Samyn N, De Boeck G, Crimele V, et al. Detection of flunitrazepam and 7-aminoflunitrazepam in oral fluid after controlled administration of rohypnol. J Anal Toxicol. 2002;26(4):211-215.

15. Schwartz RR, Milteer R, LeBeau MA. Drug Facilitated Sexual Assault ('Date Rape'). South Med J. 2000;93(6):558-561.

16. Smith J, Metters J, Kampouris D, et al. Forensic electrochemistry: The electro analytical sensing of Rohypnol (flunitrazepam) using screenprinted graphite electrodes without recourse for electrode or sample pre treatment. Analyst. 2013;138(20):6185-6191.

17. Students Develop Nail Polish That Can Detect Date Rape Drugs. USA: IFL Science; 2017.

18. United Nations Office on Drugs and Crime. USA: World Drug Report, United Nations Publication; 2008. 